\title{
ANALISIS PENGADAAN BAHAN BAKU DAN NILAI TAMBAH AGROINDUSTRI KERIPIK UBI KAYU DI KECAMATAN WAY JEPARA KABUPATEN LAMPUNG TIMUR
}

\author{
(Analysis Of Procurement Raw Material and Value Added Of Cassava Chips Agroindustry In Way Jepara \\ Sub-district East Lampung Regency)
}

Ekawati Wahyu Kusuma, Sudarma Widjaya, Suriaty Situmorang

Jurusan Agribisnis, Fakultas Pertanian, Universitas Lampung, Jl. Prof. Dr. Soemantri Brodjonegoro No.1 Bandar Lampung 35145, e-mail: suriaty.situmorang@fp.unila.ac.id

\begin{abstract}
This research aims to analyze the procurement of raw material, added value, and the factors causing inactivity of 18 cassava chips agroindustries. This research was conducted in Way Jepara Sub-district, East Lampung Regency in May -July 2018. Respondents were active and non-active cassava chips agroindustries in Way Jepara District. Procurement of raw materials is analyzed using six-component method. The added value is analyzed use Hayami's method, and the cause of inactivity of the 18 cassava chips agroindustries is analyzed qualitatively. The results showed that the procurement of raw materials with six components, namely time, place, price, quantity, quality, and type of active agroindustry is appropriate, because it is in line with the expectations of each active agroindustry. Three active agroindustries have a positive added value $(N T>0)$ can absorb labor, and can increase the income of the community around the agroindustry. The main factors causing the inactivity of 18 cassava chips agroindustries in Way Jepara Sub-district in production are less extensive product marketing coverage and low level of demand for the chips produced.
\end{abstract}

Key words: added value, agroindustry, cassava, raw material

\section{PENDAHULUAN}

Sektor pertanian menjadi salah satu sektor yang berperan penting dalam pembangunan nasional. Sektor pertanian sudah terbukti sebagai sektor yang dapat diandalkan dalam pemulihan perekonomian nasional, karena dapat memberikan kontribusi pada penerimaan Produk Domestik Bruto (PDB). Komoditas pertanian yang memiliki potensi cukup besar untuk dikembangkan adalah ubi kayu. Seiring berkembangnya teknologi, ubi kayu diolah menjadi berbagai jenis olahan makanan. Aneka olahan makanan berbahan baku ubi kayu pada agroindustri di Kecamatan Way Jepara adalah gethuk, kerupuk, nasi tiwul, dan keripik. Produk olahan ubi kayu yang paling banyak diproduksi adalah keripik. Salah satu kecamatan yang memproduksi keripik ubi kayu di Lampung Timur adalah Way Jepara. Berdasarkan data primer tahun 2017, sebanyak 18 agroindustri keripik ubi kayu di Way Jepara tidak lagi berproduksi, dan hanya terdapat tiga agroindustri yang masih aktif berproduksi, yaitu UKS, MS, dan $\mathrm{S}$ serta memiliki keberlanjutan usaha.

Agroindustri keripik di Kecamatan Way Jepara relatif banyak, sehingga potensial meningkatkan jumlah permintaan terhadap ubi kayu. Agroindustri sebagai salah satu industri pengolahan diharapkan mampu memenuhi permintaan konsumen dari segi kualitas dan kuantitas produk yang dihasilkan. Kuantitas bahan baku agroindustri sebaiknya jangan terlalu banyak, karena produk pertanian mudah rusak bila disimpan terlalu lama. Sebaliknya, bahan baku tidak boleh terlalu sedikit, karena akan menyebabkan agroindustri kekurangan bahan baku, dan tidak berproduksi. Jumlah bahan baku yang dimiliki pelaku agroindustri harus sesuai dengan kemampuan agroindustri berproduksi. Agar pelaku agroindustri keripik ubi kayu tidak mengalami kerugian, maka perlu diperhatikan bagaimana pengadaan bahan baku ubi kayu pada agroindustri keripik ubi kayu.

Proses pengolahan ubi kayu mentah menjadi barang jadi atau setengah jadi akan menciptakan nilai tambah, misalnya kegiatan pengolahan bahan baku ubi kayu menjadi keripik. Akan tetapi,dari 21 agroindustri keripik ubi kayu di Way Jepara, sebanyak 18 agroindustri tidak berproduksi lagi. Oleh karena itu, perlu dilakukan analisis nilai tambah dan faktor-faktor yang menjadi penyebab ketidakaktifan agroindustri keripik ubi kayu di Kecamatan Way Jepara.

Tujuan dari penelitian ini adalah untuk mengetahui pengadaan bahan baku, menganalisis nilai tambah, 
dan menganalisis faktor penyebab ketidakaktifan 18 agroindustri keripik ubi kayu yang sudah tidak aktif lagi di Kecamatan Way Jepara.

\section{METODE PENELITIAN}

Metode penelitian yang digunakan adalah metode sensus. Lokasi penelitian dipilih secara purposive (sengaja) pada tiga agroindustri aktif dan 18 agroindustri non-aktif keripik ubi kayu di Kecamatan Way Jepara. Pengumpulan data dilakukan pada bulan Mei-Juli 2018. Terdapat dua jenis data yang digunakan dalam penelitian, yaitu data primer dan data sekunder. Data primer diperoleh melalui wawancara dengan pemilik agroindustri, menggunakan kuesioner, sedangkan data sekunder diperoleh dari lembaga/instansi terkait, dan literatur-literatur yang berhubungan dengan penelitian ini.

Analisis yang digunakan untuk menjawab tujuan pertama adalah analisis deskriptif kualitatif mengenai pengadaan bahan baku berupa pelaksanaan enam tepat, pada tiga agroindustri keripik ubi kayu yang aktif di Way Jepara. Menurut Assauri (1999) pengadaan bahan baku terdapat enam faktor penting yang perlu diperhatikan, dimana bahan baku tersebut harus sesuai dengan tepat kuantitas, tepat kualitas, tepat tempat, tepat waktu, tepat harga, dan tepat jenis.

Analisis yang digunakan untuk menjawab tujuan kedua adalah analisis nilai tambah Hayami (1987). Nilai tambah adalah pertambahan nilai suatu komoditas karena adanya input fungsional pada komoditas yang bersangkutan. Nilai tambah adalah selisih yang diperoleh antara komoditas yang mendapat perlakuan tertentu dengan nilai pengorbanan yang diberikan selama proses berlangsung. Prosedur perhitungan nilai tambah metode Hayami disajikan pada Tabel 1.

Analisis yang digunakan untuk menjawab tujuan ketiga adalah analisis deskriptif kualitatif mengenai faktor penyebab ketidakaktifan 18 agroindustri keripik ubi kayu di Way Jepara, meliputi informasi pengadaan bahan baku, jumlah pemesanan, kuantitas dan kualitas produk keripik yang dihasilkan oleh agroindustri, segmentasi pasar, dan lain-lain.
Tabel 1. Prosedur perhitungan nilai tambah metode Hayami

\begin{tabular}{|c|c|c|}
\hline No. & Variabel & Nilai \\
\hline I. & Output, Input, Harga & \\
\hline 1. & Output (kg/produksi) & A \\
\hline 2. & Bahan baku (kg/produksi) & B \\
\hline 3. & Tenaga kerja (HOK/produksi) & $\mathrm{C}$ \\
\hline 4. & Faktor konversi & $\mathrm{D}=\mathrm{A} / \mathrm{B}$ \\
\hline 5. & Koefisien tenaga kerja & $\mathrm{E}=\mathrm{C} / \mathrm{B}$ \\
\hline 6. & Harga output (Rp/Kg/produksi) & $\mathrm{F}$ \\
\hline 7. & $\begin{array}{l}\text { Upah rata-rata tenaga kerja } \\
(\mathrm{Rp} / \mathrm{HOK})\end{array}$ & G \\
\hline II. & $\begin{array}{l}\text { Pendapatan dan Keuntungan } \\
\text { (Rp/kg/produksi) }\end{array}$ & \\
\hline 8. & Harga bahan baku & $\mathrm{H}$ \\
\hline 9. & $\begin{array}{l}\text { Sumbangan input lain } \\
\text { (per kg bahan baku) }\end{array}$ & I \\
\hline 10. & Nilai output & $\mathrm{J}=\mathrm{D} \times \mathrm{F}$ \\
\hline \multirow[t]{2}{*}{11.} & Nilai tambah & $\mathrm{K}=\mathrm{J}-\mathrm{I}-\mathrm{H}$ \\
\hline & Rasio nilai tambah & $\mathrm{L} \%=(\mathrm{K} / \mathrm{J}) \times 100 \%$ \\
\hline \multirow[t]{2}{*}{12.} & Imbalan tenaga kerja & $\mathrm{M}=\mathrm{E} \times \mathrm{G}$ \\
\hline & Bagian tenaga kerja & $\mathrm{N} \%=(\mathrm{M} / \mathrm{K}) \times 100 \%$ \\
\hline \multirow[t]{2}{*}{13} & Keuntungan & $\mathrm{O}=\mathrm{K}-\mathrm{M}$ \\
\hline & Tingkat keuntungan & $\mathrm{P} \%=(\mathrm{O} / \mathrm{K}) \times 100 \%$ \\
\hline III. & Balas Jasa Faktor Produksi & \\
\hline \multirow[t]{4}{*}{14.} & Margin & $\mathrm{Q}=\mathrm{J}-\mathrm{H}$ \\
\hline & Kuntungan & $\mathrm{R}=\mathrm{O} / \mathrm{Q} \times 100 \%$ \\
\hline & Tenaga kerja & $\mathrm{S}=\mathrm{M} / \mathrm{Q} \times 100 \%$ \\
\hline & Input lain & $\mathrm{T}=\mathrm{I} / \mathrm{Q} \times 100 \%$ \\
\hline
\end{tabular}

Keterangan :

A = Output atau total produksi keripik ubi kayu yang di hasilkan oleh agroindustri.

$\mathrm{B}=$ Input atau bahan baku yang digunakan untuk memproduksi keripik adalah ubi kayu.

$\mathrm{C}=$ Tenaga kerja yang digunakan dalam memproduksi keripik yang dihitung dalam satuan Hari Orang Kerja dalam satu periode analisis.

$\mathrm{F}=$ Harga produk yang berlaku pada satu periode analisis.

$\mathrm{G}=$ Jumlah upah rata-rata yang diterima oleh pekerja dalam setiap satu periode produksi yang dihitung berdasarkan upah per HOK.

$\mathrm{H}$ = Harga input bahan baku ubi kayu per kilogram pada saat periode analisis.

$\mathrm{I}=$ Sumbangan/biaya input lainnya yang terdiri dari biaya bahan baku penolong, biaya penyusutan, dan biaya pengemasan per kg bahan baku. 


\section{HASIL DAN PEMBAHASAN}

\section{Karakteristik Responden}

Responden pada penelitian berjumlah 21 orang pemilik agroindustri keripik ubi kayu yang terdiri dari tiga orang pemilik agroindustri aktif dan 18 orang pemilik agroindustri non-aktif. Umur responden penelitian bervariasi mulai dari umur 32 tahun sampai dengan umur 45 tahun, sehingga dapat dikatakan bahwa umur responden tergolong ke dalam umur produktif untuk mengembangkan agroindustri keripik ubi kayu. Rata-rata tingkat pendidikan responden pemilik agroindustri adalah SMA. Pengalaman usaha yang dimiliki oleh responden dapat dikatakan belum cukup terampil, karena rata-rata responden memiliki pengalaman kerja kurang dari lima tahun. Jumlah tanggungan keluarga responden pada penelitian ini cukup beragam yaitu $3-5$ orang.

\section{Pengadaan Bahan Baku}

Bahan baku yang digunakan oleh agroindustri keripik ubi kayu adalah ubi kayu makan dengan nama ilmiah Manihot esculenta Crantz. Ubi kayu adalah salah satu jenis tanaman umbi-umbian yang mempunyai tingkat ketuaan, kekerasan, dan kandungan pati (Ayu 2012). Pada umumnya, dengan bertambahnya tingkat ketuaan, umbi akan semakin keras teksturnya, karena kandungan pati yang semakin meningkat. Apabila terlalu tua kandungan seratnya bertambah, sedangkan patinya menurun (Kartasapoetra 1994). Berdasarkan hal tersebut, maka pengendalian bahan baku pada agroindustri keripik ubi kayu perlu diperhatikan, karena berkaitan dengan umur panen ubi kayu yang akan digunakan untuk produksi dapat mempengaruhi kualitas keripik yang akan dihasilkan.

Pengadaan bahan baku pada agroindustri keripik ubi kayu di Way Jepara melibatkan beberapa pihak, yaitu pemasok bahan baku berupa mitra ataupun pedagang pengumpul biasa, agroindustri keripik ubi kayu, dan konsumen. Pengadaan bahan baku yang cukup pada agroindustri keripik ubi kayu di Kecamatan Way Jepara diharapkan dapat memperlancar proses kegiatan produksi, dan menghindari terjadinya kelebihan atau kekurangan bahan baku. Dari hasil wawancara dengan pemilik agroindustri keripik ubi kayu diperoleh bahwa bahan baku keripik ubi kayu berasal dari Desa
Sumber Sari dan Desa Sri Katon Kabupaten Lampung Timur. Harga bahan baku berkisar antara Rp1.700,00 sampai Rp1.800,00 per kilogram, dengan biaya pemesanan adalah Rp25.000,00 untuk 1 - 4 ton ubi kayu setiap satu kali angkut. Bahan baku ubi kayu diperlukan dalam jumlah yang cukup dan menjadi faktor penting dalam keberlanjutan usaha agroindustri. Bahan baku sebaiknya tidak terlalu banyak dan tidak dalam jumlah sedikit. Ubi kayu merupakan tanaman pertanian yang tidak dapat disimpan dalam jangka waktu lama, karena bersifat mudah rusak dan busuk.

\section{A. Tepat Waktu}

Waktu pengadaan bahan baku pada Agroindustri UKS, MS, dan S disesuaikan dengan kebutuhan bahan baku dalam proses produksi. Waktu ketersediaan bahan baku perlu diperhatikan agar kualitas ubi kayu yang digunakan baik, sehingga agroindustri keripik tidak mengalami kendala yang diakibatkan oleh bahan baku. Dalam waktu satu bulan, agroindustri melakukan pemesanan bahan baku selama empat kali, pada Agroindustri UKS dan S setiap hari Jumat, sedangkan pada Agroindustri MS setiap hari Kamis. Bahan baku yang dipesan akan tiba sehari setelah dipesan, Agroindustri UKS dan S setiap hari Sabtu, sedangkan Agroindustri MS setiap hari Jumat. Tiga agroindustri keripik ubi kayu memiliki persediaan bahan baku yang cukup dengan melakukan manajemen waktu terhadap pemesanan bahan baku sebelum persediaan bahan baku ubi kayu habis. Ubi kayu tidak langsung diolah untuk menghasilkan kualitas keripik yang baik. Bahan baku yang dipesan Agroindustri UKS, MS, dan S selalu dapat tercukupi, karena telah melakukan kerjasama dengan pemasok bahan baku ubi kayu.

Lokasi agroindustri dengan pemasok bahan baku tidak terlalu jauh, sehingga pihak agroindustri tidak mengalami kesulitan dan tidak harus menunggu dalam waktu yang lama untuk memperoleh bahan baku ubi kayu tersebut. Oleh karena itu, dapat dinyatakan bahwa pengadaan bahan baku dalam komponen waktu sudah sesuai dengan yang diharapkan oleh Agroindustri UKS, MS, dan S. Artinya, tiga agroindustri telah melakukan kegiatan pengadaan bahan baku dengan tepat waktu. Pengadaan bahan baku pada agroindustri keripik ubi kayu yang masih aktif di Kecamatan Way Jepara dapat dilihat pada Tabel 2. 
Tabel 2. Pengadaan bahan baku pada agroindustri keripik ubi kayu yang masih aktif di Kecamatan Way Jepara Kabupaten Lampung Timur

\begin{tabular}{|c|c|c|c|c|c|c|}
\hline \multirow{2}{*}{$\begin{array}{l}\text { Komponen } \\
\text { pengadaan } \\
\text { bahan baku }\end{array}$} & \multicolumn{2}{|c|}{ Agroindustri UKS } & \multicolumn{2}{|c|}{ Agroindustri MS } & \multicolumn{2}{|c|}{ Agroindustri S } \\
\hline & Harapan & Kenyataan & Harapan & Kenyataan & Harapan & Kenyataan \\
\hline Waktu & $\begin{array}{l}\text { Pengadaan } \\
\text { bahan baku } \\
\text { dilakukan } 4 \text { kali } \\
\text { dalam sebulan }\end{array}$ & $\begin{array}{l}\text { Pengadaan bahan } \\
\text { baku dilakukan } 4 \\
\text { kali dalam } \\
\text { sebulan }\end{array}$ & $\begin{array}{l}\text { Pengadaan } \\
\text { bahan baku } \\
\text { dilakukan } 4 \\
\text { kali dalam } \\
\text { sebulan }\end{array}$ & $\begin{array}{l}\text { Pengadaan bahan } \\
\text { baku dilakukan } 4 \\
\text { kali dalam } \\
\text { sebulan }\end{array}$ & $\begin{array}{l}\text { Pengadaan } \\
\text { bahan baku } \\
\text { dilakukan } 4 \\
\text { kali dalam } \\
\text { sebulan }\end{array}$ & $\begin{array}{l}\text { Pengadaan bahan } \\
\text { baku dilakukan } 4 \\
\text { kali dalam sebulan }\end{array}$ \\
\hline Tempat & $\begin{array}{l}\text { Lokasi untuk } \\
\text { memperoleh } \\
\text { bahan baku } \\
\text { mudah di } \\
\text { jangkau }\end{array}$ & $\begin{array}{l}\text { Lokasi untuk } \\
\text { memperoleh } \\
\text { bahan baku } \\
\text { mudah di jangkau }\end{array}$ & $\begin{array}{l}\text { Lokasi untuk } \\
\text { memperoleh } \\
\text { bahan baku } \\
\text { mudah di } \\
\text { jangkau }\end{array}$ & $\begin{array}{l}\text { Lokasi untuk } \\
\text { memperoleh } \\
\text { bahan baku } \\
\text { mudah di } \\
\text { jangkau }\end{array}$ & $\begin{array}{l}\text { Lokasi untuk } \\
\text { memperoleh } \\
\text { bahan baku } \\
\text { mudah di } \\
\text { jangkau }\end{array}$ & $\begin{array}{l}\text { Lokasi untuk } \\
\text { memperoleh bahan } \\
\text { baku mudah di } \\
\text { jangkau }\end{array}$ \\
\hline Kualitas & $\begin{array}{l}\text { Ubi kayu yang } \\
\text { digunakan } \\
\text { berkualitas baik, } \\
\text { tidak pahit, } \\
\text { berumbi besar, } \\
\text { tidak cacat, dan } \\
\text { tidak busuk }\end{array}$ & $\begin{array}{l}\text { Ubi kayu yang } \\
\text { digunakan } \\
\text { berkualitas baik, } \\
\text { tidak pahit, } \\
\text { berumbi besar, } \\
\text { tidak cacat, dan } \\
\text { tidak busuk }\end{array}$ & $\begin{array}{l}\text { Ubi kayu } \\
\text { berkualitas } \\
\text { baik, tidak } \\
\text { pahit, berumbi } \\
\text { sedang dan } \\
\text { lurus, tidak } \\
\text { rusak atau } \\
\text { busuk }\end{array}$ & $\begin{array}{l}\text { Ubi kayu } \\
\text { berkualitas baik, } \\
\text { tidak pahit, } \\
\text { berumbi sedang } \\
\text { dan lurus, tidak } \\
\text { rusak atau busuk }\end{array}$ & $\begin{array}{l}\text { Ubi kayu } \\
\text { berkualitas } \\
\text { baik, umbi } \\
\text { berukuran } \\
\text { besar, tidak } \\
\text { rusak, dan } \\
\text { tidak busuk }\end{array}$ & $\begin{array}{l}\text { Ubi kayu } \\
\text { berkualitas baik, } \\
\text { umbi berukuran } \\
\text { besar, tidak rusak, } \\
\text { dan tidak busuk }\end{array}$ \\
\hline Kuantitas & $\begin{array}{l}\text { Bahan baku } \\
\text { tersedia } 3.500 \\
\mathrm{~kg} / \text { produksi }\end{array}$ & $\begin{array}{l}\text { Bahan baku } \\
\text { tersedia } 4.000 \\
\mathrm{~kg} / \text { produksi }\end{array}$ & $\begin{array}{l}\text { Bahan baku } \\
\text { tersedia } 2.000 \\
\mathrm{~kg} / \text { produksi }\end{array}$ & $\begin{array}{l}\text { Bahan baku } \\
\text { tersedia } 2.500 \\
\mathrm{~kg} / \text { produksi }\end{array}$ & $\begin{array}{l}\text { Bahan baku } \\
\text { tersedia } 2.500 \\
\mathrm{~kg} / \text { produksi }\end{array}$ & $\begin{array}{l}\text { Bahan baku } \\
\text { tersedia } 3.000 \\
\mathrm{~kg} / \text { produksi }\end{array}$ \\
\hline Harga & $\begin{array}{l}\text { Harga ubi kayu } \\
\text { sebesar } \\
\text { Rp1.700- } \\
\text { Rp1.800 per kg }\end{array}$ & $\begin{array}{l}\text { Harga ubi kayu } \\
\text { sebesar Rp1.700 } \\
\text { per kg }\end{array}$ & $\begin{array}{l}\text { Harga ubi kayu } \\
\text { Rp1.700- } \\
\text { Rp1.800 per kg }\end{array}$ & $\begin{array}{l}\text { Harga ubi kayu } \\
\text { sebesar Rp1.800 } \\
\text { per kg }\end{array}$ & $\begin{array}{l}\text { Harga ubi kayu } \\
\text { Rp1.700- } \\
\text { Rp1.800 per kg }\end{array}$ & $\begin{array}{l}\text { Harga ubi kayu } \\
\text { sebesar Rp1.800 } \\
\text { per kg }\end{array}$ \\
\hline Jenis & $\begin{array}{l}\text { Bahan baku ubi } \\
\text { kayu yang } \\
\text { berkualitas baik, } \\
\text { tekstur keripik } \\
\text { ubi kayu renyah, } \\
\text { tidak pahit, dan } \\
\text { bahan } \\
\text { penunjang } \\
\text { berkualitas baik }\end{array}$ & $\begin{array}{l}\text { Bahan baku ubi } \\
\text { kayu berkualitas, } \\
\text { bahan penunjang } \\
\text { yang digunakan } \\
\text { adalah jenis yang } \\
\text { masih segar dan } \\
\text { baik kualitasnya }\end{array}$ & $\begin{array}{l}\text { Bahan baku ubi } \\
\text { kayu yang } \\
\text { berkualitas } \\
\text { baik, tekstur } \\
\text { keripik ubi } \\
\text { kayu renyah, } \\
\text { tidak pahit, } \\
\text { danbahan } \\
\text { penunjang } \\
\text { berkualitas baik }\end{array}$ & $\begin{array}{l}\text { Bahan baku ubi } \\
\text { kayu berkualitas, } \\
\text { bahan penunjang } \\
\text { yang digunakan } \\
\text { adalah jenis yang } \\
\text { masih segar dan } \\
\text { baik kualitasnya }\end{array}$ & $\begin{array}{l}\text { Bahan baku ubi } \\
\text { kayu yang } \\
\text { berkualitas } \\
\text { baik, tekstur } \\
\text { keripik ubi } \\
\text { kayu renyah, } \\
\text { tidak pahit, dan } \\
\text { bahan } \\
\text { penunjang } \\
\text { berkualitas } \\
\text { baik }\end{array}$ & $\begin{array}{l}\text { Bahan baku ubi } \\
\text { kayu berkualitas, } \\
\text { bahan penunjang } \\
\text { yang digunakan } \\
\text { adalah jenis yang } \\
\text { masih segar dan } \\
\text { baik kualitasnya }\end{array}$ \\
\hline
\end{tabular}

\section{B. Tepat Tempat}

Tempat adalah lokasi dimana pihak agroindustri memperoleh bahan baku yang digunakan untuk kegiatan produksi agroindustri. Pemilihan tempat pembelian bahan baku ubi kayu pada Agroindustri UKS, MS, dan S sudah tepat, karena agroindustri memperoleh bahan baku pada lokasi yang mudah dijangkau. Bahan baku ubi kayu makan diperoleh agroindustri dengan cara membeli kepada para pemasok ubi kayu makan di Lampung Timur, yaitu Bapak Lehan dan Bapak Nanang. Pemasok ubi kayu dan pemilik agroindustri telah bekerja sama dan menjadi langganan, sehingga terjalin hubungan yang baik antara pemilik agroindustri dengan para pemasok ubi kayu tersebut. Selain itu, tempat pembelian bahan baku ubi kayu mudah dijangkau oleh agroindustri, sehingga memudahkan agroindustri dalam memperoleh bahan baku. Komponen pengadaan bahan baku berupa tempat sudah sesuai dengan yang diharapkan Agroindustri UKS, MS, dan S. Artinya, Agroindustri UKS, MS, dan $\mathrm{S}$ telah melakukan kegiatan pengadaan bahan baku dengan tepat tempat, karena jarak antara agroindustri dengan pemasok ubi kayu dekat.

\section{Tepat Harga}

Biaya yang dikeluarkan untuk pembelian bahan baku pada proses pengolahan biasanya menjadi biaya paling besar yang dikeluarkan oleh agroindustri. Harga bahan baku adalah harga beli 
bahan baku yang harus dikeluarkan oleh pemilik agroindustri dengan tujuan memenuhi pengadaan bahan baku untuk memproduksi keripik, yang diukur dalam satuan rupiah (Rp). Harga bahan baku ubi kayu dari pemasok kepada pemilik agroindustri berbeda-beda, yaitu Rp1.700,00 Rp1.800,00 per kilogram. Perbedaan harga bahan baku disebabkan oleh jarak lokasi pemasok dengan agroindustri. Akan tetapi, ketersediaan ubi kayu makan selalu dapat terpenuhi dalam jumlah yang cukup. Artinya, Agroindustri UKS, MS, dan S telah melakukan kegiatan pengadaan bahan baku dengan tepat harga.

\section{Tepat Jenis}

Bahan baku ubi kayu yang digunakan pada Agroindustri UKS, MS, dan S adalah jenis ubi kayu makan yang berkualitas. Agroindustri berharap menggunakan jenis ubi kayu varietas Singgah. Menurut Ntui, Uyoh, dan Affangideh (2006) varietas Singgah memiliki batang utama yang besar dengan ruas yang panjang, tetapi tidak bercabang, rasa umbi manis, warna daging umbi putih, dan berumbi besar. Hal ini dibuktikan dengan hasil keripik ubi kayu yang berkualitas baik pula, tekstur keripik ubi kayu renyah dan tidak pahit. Ubi kayu yang digunakan sebagai bahan baku agroindustri keripik sudah tepat jenis, karena menggunakan ubi kayu varietas Singgah yang sesuai standar jenis ubi kayu yang ditetapkan Agroindustri UKS, MS, dan S. Begitu pula dengan bahan penunjang yang digunakan adalah jenis yang masih segar dan baik kualitasnya untuk digunakan dalam proses produksi. Artinya, Agroindustri UKS, MS, dan $\mathrm{S}$ telah melakukan kegiatan pengadaan bahan baku dengan tepat jenis.

\section{E. Tepat Kuantitas}

Kuantitas atau jumlah bahan baku yang digunakan akan mempengaruhi jumlah output yang dihasilkan. Jumlah bahan baku diharapkan mampu mencukupi target ketersediaan bahan baku pada agroindustri, sehingga dapat mencukupi target output yang ingin dicapai oleh agroindustri. Agroindustri UKS, MS, dan S telah memiliki jumlah bahan baku yang tepat, karena antara harapan dan kenyataan jumlah yang diinginkan agroindustri telah tercapai, dan bahan baku selalu tersedia apabila agroindustri melakukan kegiatan produksi. Kapasitas produksi yang diharapkan Agroindustri UKS, MS, dan S masing-masing yaitu $3.500,2.000$, dan 2.500 kilogram per produksi. Bahan baku ubi kayu yang tersedia selalu dapat mencukupi kebutuhan produksi agroindustri. Berdasarkan ketersediaan bahan baku ubi kayu yang selalu tercukupi hingga saat ini, dapat dinyatakan bahwa agroindustri keripik ubi kayu telah melakukan kegiatan pengadaan bahan baku dengan tepat kuantitas.

\section{F. Tepat Kualitas}

Kualitas ubi kayu yang digunakan sebagai bahan baku dalam agroindustri keripik ubi kayu di daerah penelitian dapat berpengaruh terhadap produk keripik yang dihasilkan. Ubi kayu yang dijadikan bahan baku agroindustri harus sesuai dengan standar kualitas yang ditetapkan oleh agroindustri, seperti ubi kayu segar dan baru dipanen, cenderung lurus, ukuran umbi ubi kayu besar, renyah dan daging umbinya empuk, kadar patinya cukup tinggi, kulit ari mudah dikupas, tidak cacat, dan tidak busuk, sehingga dapat dinyatakan Agroindustri UKS, MS, dan S telah melakukan pengadaan bahan baku dengan tepat kualitas.

\section{Analisis Nilai Tambah}

Nilai tambah produk keripik ubi kayu dihitung dalam satu kali proses produksi. Bahan baku ubi kayu yang digunakan untuk memproduksi keripik adalah ubi kayu segar. Harga ubi kayu segar tingkat petani pada bulan September 2018 di Lampung Timur adalah Rp650,00/kg, sehingga harga ubi kayu segar tersebut tergolong rendah, padahal di tingkat pedagang pengumpul tinggi, yaitu Rp1.700,00/kg sampai Rp1.800,00/kg. Harga di tingkat pedagang pengumpul tinggi disebabkan oleh adanya beberapa perlakuan terhadap ubi kayu sebelum dijual, seperti pembersihan pada sisa-sisa tanah yang masih banyak menempel, dan pemilihan ubi kayu berdasarkan ukurannya. Harga output keripik ubi kayu di Kecamatan Way Jepara adalah Rp34.000,00 per kilogram. Agroindustri UKS, MS, dan S, menjual keripik dengan harga sama. Persamaan harga output tersebut mempertimbangkan lokasi agroindustri yang berada pada satu kecamatan, sehingga terjadi kesepakatan antara ketiga agroindustri untuk menentukan besarnya harga output keripik ubi kayu di Kecamatan Way Jepara.

Lokasi Agroindustri UKS, MS, dan S, yang tidak terlalu jauh menyebabkan tiga agroindustri tersebut memiliki kesamaan terhadap harga jual dan upah tenaga kerja yang berlaku. Kesamaan ini bertujuan untuk berlaku menyesuaikan harga jual dan upah tenaga kerja yang di wilayah sekitar agroindustri, agar dapat bersaing dengan agroindustri lain. Nilai 
keripik ubi kayu yang dihasilkan dengan pengolahan setiap kilogram ubi kayu adalah sama, karena nilai output ini diperoleh dari hasil perkalian faktor konversi dengan harga produk, yang pada masing-masing agroindustri juga memiliki nilai yang sama.

Hasil penelitian menunjukkan bahwa nilai tambah usaha Agroindustri keripik ubi kayu di Kecamatan Way Jepara tahun 2018 memberikan nilai tambah yang positif terhadap pengolahan ubi kayu menjadi keripik ubi kayu. Pengolahan ubi kayu menjadi keripik ubi kayu dapat menyerap banyak tenaga kerja, sehingga memberikan kesempatan kerja bagi masyarakat di sekitar agroindustri dan membantu perekonomian masyarakat dengan meningkatkan pendapatan pemilik agroindustri dan tenaga kerja luar keluarga sebagai anggota masyarakat. Hasil perhitungan analisis nilai tambah agroindustri keripik ubi kayu di Way Jepara per produksi pada Tahun 2017 dapat dilihat pada Tabel 3. Berdasarkan Tabel 3 dapat diketahui nilai tambah pada Agroindustri UKS, MS, dan S lebih besar dibandingkan dengan Agroindustri MS dan Agroindustri S. Artinya, agroindustri keripik ubi kayu di Way Jepara memberikan nilai tambah (positif). Hal ini sejalan dengan penelitian Febriyanti, Affandi, dan Kalsum (2017), serta Sari, Hasyim, dan Widjaya (2018) yang menyatakan bahwa produk keripik pisang yang diproduksi oleh agroindustri menghasilkan nilai tambah yang positif.

Nilai balas jasa pemilik terhadap tenaga kerja lebih kecil daripada nilai keuntungan yang diperoleh, sehingga Agroindustri UKS, MS, dan S, termasuk agroindustri padat modal. Hasil penelitian ini sama seperti yang dilakukan Febriyanti, et.al. (2017) yang menunjukkan bahwa sifat agroindustri keripik pisang lebih cenderung sebagai usaha yang bersifat padat modal. Rasio nilai tambah keripik ubi kayu pada Agroindustri UKS, MS, dan S di Kecamatan Way Jepara masing-masing sebesar 74,06 persen, 73,61 persen, dan 73,98 persen. Apabila dibandingkan dengan penelitian Sagala, Affandi, dan Ibnu (2013) dengan rasio nilai tambah sebesar 34,57 persen dapat diketahui bahwa rasio nilai tambah pada penelitian ini lebih besar dibanding penelitian terdahulu.

Tabel 3. Nilai tambah agroindustri aktif di Kecamatan Way Jepara Kabupaten Lampung Timur per periode produksi, tahun 2017

\begin{tabular}{|c|c|c|c|c|c|}
\hline \multirow{2}{*}{\multicolumn{2}{|c|}{$\begin{array}{c}\text { Variabel } \\
\text { Output, Input dan Harga }\end{array}$}} & \multirow{3}{*}{$\begin{array}{l}\text { Koefisien } \\
\text { A }\end{array}$} & \multicolumn{3}{|c|}{ Nilai tambah Agroindustri } \\
\hline & & & \multirow{2}{*}{$\frac{\mathrm{UKS}}{2.520,00}$} & \multirow{2}{*}{$\begin{array}{l}\text { MS } \\
1.530,00\end{array}$} & \multirow{2}{*}{$\begin{array}{r}\mathrm{S} \\
1.890,00\end{array}$} \\
\hline 1. & Output (Kg/produksi) & & & & \\
\hline 2. & Bahan baku (Kg/produksi) & $\mathrm{B}$ & $3.500,00$ & $2.125,00$ & $2.625,00$ \\
\hline 3. & Tenaga Kerja (HOK/produksi) & $\mathrm{C}$ & 32,88 & 14,75 & 24,13 \\
\hline 4. & Faktor Konversi & $\mathrm{D}=\mathrm{A} / \mathrm{B}$ & 0,72 & 0,72 & 0,72 \\
\hline 5. & Koefisien Tenaga Kerja & $\mathrm{E}=\mathrm{C} / \mathrm{B}$ & 0,01 & 0,01 & 0,01 \\
\hline 6. & Harga Output (Rp/Kg/produksi) & $\mathrm{F}$ & $34.000,00$ & $34.000,00$ & $34.000,00$ \\
\hline 7. & Upah Rata-rata Tenaga Kerja (Rp/HOK) & $\mathrm{G}$ & $40.000,00$ & $40.000,00$ & $40.000,00$ \\
\hline \multicolumn{6}{|c|}{ Pendapatan dan Keuntungan (Rp/Kg/produksi) } \\
\hline 8. & Harga bahan baku & $\mathrm{H}$ & $1.700,00$ & $1.800,00$ & $1.700,00$ \\
\hline 9. & Sumbangan input lain / kg bahan baku & I & $4.650,72$ & $4.660,39$ & $4.669,98$ \\
\hline 10. & Nilai Output & $\mathrm{J}=\mathrm{D} \times \mathrm{F}$ & $24.480,00$ & $24.480,00$ & $24.480,00$ \\
\hline \multirow[t]{2}{*}{11.} & a. Nilai Tambah & $\mathrm{K}=\mathrm{J}-\mathrm{I}-\mathrm{H}$ & $18.129,28$ & $18.019,61$ & $18.110,02$ \\
\hline & b. Rasio Nilai Tambah & $\mathrm{L}=(\mathrm{K} / \mathrm{J}) \times 100(\%)$ & 74,06 & 73,61 & 73,98 \\
\hline \multirow[t]{2}{*}{12.} & a. Imbalan Tenaga Kerja & $M=E \times G$ & 400,00 & 400,00 & 400,00 \\
\hline & b. Bagian Tenaga Kerja & $N=(M / K) \times 100(\%)$ & 2,21 & 2,22 & 2,21 \\
\hline \multirow[t]{2}{*}{13.} & a. Keuntungan & $\mathrm{O}=\mathrm{K}-\mathrm{M}$ & $17.729,28$ & $17.620,72$ & $17.710,02$ \\
\hline & b. Tingkat keuntungan & $\mathrm{P}=\mathrm{O} / \mathrm{K} \times 100(\%)$ & 97,79 & 97,79 & 97,79 \\
\hline \multicolumn{6}{|c|}{ Balas Jasa Pemilik Faktor-faktor Produksi } \\
\hline \multirow[t]{4}{*}{14.} & Marjin Keuntungan & $\mathrm{Q}=\mathrm{J}-\mathrm{H}$ & $22.780,00$ & $22.680,00$ & $22.780,00$ \\
\hline & a. Keuntungan & $\mathrm{R}=\mathrm{O} / \mathrm{Q} \times 100 \%$ & 77,83 & 77,69 & 77,74 \\
\hline & b. Tenaga Kerja & $\mathrm{S}=\mathrm{M} / \mathrm{Q} \times 100 \%$ & 1,76 & 1,76 & 1,76 \\
\hline & c. Input lain & $\mathrm{T}=\mathrm{I} / \mathrm{Q} \times 100 \%$ & 20,42 & 20,55 & 20,50 \\
\hline
\end{tabular}


Keuntungan yang diperoleh keripik ubi kayu pada Agroindustri UKS, MS, dan S di Kecamatan Way Jepara masing-masing sebesar Rp17.729,28; Rp17.620,72; dan Rp17.710,02 per kilogram dengan tingkat keuntungan sebesar 97,79 persen. Nilai keuntungan tersebut lebih besar dari penelitian Maharani, Lestari, dan Kasymir (2013) yang mendapat keuntungan sebesar Rp176,50 per kilogram untuk usaha menengah dan Rp212.06 per kilogram untuk usaha kecil.

\section{Faktor Penyebab Ketidakaktifan 18 Agroindustri Keripik Ubi Kayu di Kecamatan Way Jepara Kabupaten Lampung Timur}

Kecamatan Way Jepara memiliki 21 agroindustri keripik ubi kayu yang pernah berproduksi, tetapi hanya ada tiga unit yang masih aktif berproduksi. Banyaknya jumlah agroindustri keripik diharapkan dapat meningkatkan jumlah permintaan terhadap ubi kayu, dan diharapkan dapat mendukung berkembangnya agroindustri keripik.

Faktor penyebab ketidakaktifan 18 agroindustri keripik ubi kayu di Kecamatan Way Jepara adalah agroindustri aktif yang lebih dulu berproduksi dibandingkan agroindustri non-aktif, sehingga pemasok ubi kayu lebih memilih untuk memasok ubi kayu kepada agroindustri aktif, karena antara agroindustri dan pemasok telah terjalin kerjasama yang lebih lama dibanding dengan agroindustri non-aktif. Selain itu, lingkup pemasaran agroindustri yang kurang luas menyebabkan agroindustri kecil kesulitan untuk menjual produknya, serta agroindustri non-aktif juga menjual produknya pada lingkup pemasaran yang sama dengan agroindustri aktif. Hal tersebut menyebabkan agroindustri non-aktif kalah bersaing dengan agroindustri aktif.

Agroindustri aktif telah memiliki pelanggan tetap dan jumlah permintaan produk keripik yang selalu lebih besar jika dibandingkan dengan agroindustri non-aktif. Agroindustri keripik ubi kayu yang nonaktif di Kecamatan Way Jepara memiliki hasil yang kurang baik, sehingga masyarakat umum kurang tertarik pada hasil tersebut. Di sisi lain, proses produksi tersebut juga belum memiliki izin usaha dan nomor dagang, serta memiliki tingkat permintaan (jumlah pemesanan) yang lebih sedikit dibandingkan agroindustri aktif. Pelanggan kurang tertarik untuk membeli produk agroindustri nonaktif, karena sudah terbiasa membeli keripik dari agroindustri aktif yang telah memiliki merk, dan izin usaha.
Agroindustri aktif dapat digolongkan sebagai market leader, karena menjadi agroindustri yang mampu terus berproduksi dan memiliki keberlanjutan usaha. Agroindustri keripik ubi kayu non-aktif adalah agroindustri yang memiliki skala usaha lebih kecil jika dibandingkan dengan agroindustri aktif. Produk yang dihasilkan agroindustri aktif telah menguasai pasar, karena agroindustri aktif telah berdiri lebih dulu dan telah memiliki pelanggan tetap.

Agroindustri non-aktif hanya berproduksi apabila ada pesanan saja. Jika belum atau tidak ada pelanggan yang memesan, maka agroindustri tidak berproduksi atau non-aktif. Produksi agroindustri non-aktif cenderung berupa kegiatan yang dilakukan untuk mengisi waktu luang saat harga ubi kayu relatif rendah (murah). Pada saat tidak berproduksi keripik, pemilik agroindustri non-aktif kembali melakukan pekerjaan utamanya, yaitu sebagai pegawai, petani, pemilik toko, dan lainlain. Pendapatan dari pekerjaan utama yang lebih besar dibandingkan dengan usaha agroindustri keripik ubi kayu menyebabkan pemilik agroindustri lebih memilih pekerjaan utama untuk memperoleh pendapatan bagi kebutuhan rumah tangganya. Agroindustri aktif dan non-aktif di Kecamatan Way Jepara tahun 2018 dapat dilihat pada Tabel 4.

Tabel 4. Agroindustri keripik ubi kayu yang aktif dan non-aktif di Kecamatan Way Jepara, tahun 2018

\begin{tabular}{cll}
\hline No. & \multicolumn{1}{c}{ Agroindustri aktif } & \multicolumn{1}{c}{ Alamat } \\
\hline 1. & Usaha Keluarga Sejahtera & Labuhan Ratu 2 \\
2. & Moro Seneng & Sumberjo \\
3. & Sejahtera & Sumber Marga \\
\hline \multicolumn{2}{c}{ Agroindustri Non-aktif } & \multicolumn{1}{c}{ Alamat } \\
\hline 1. & Jaya Rasa & Labuhan Ratu 1 \\
2. & Tiga Putri & Braja Asri \\
3. & Pedas Manis & Labuhan Ratu 2 \\
4. & 2 Dara & Sumberjo \\
5. & Lima Saudara & Braja Caka \\
6. & Sumber Rezeki & Sumberjo \\
7. & Maju Jaya & Braja Asri \\
8, & Karya Makmur & Jepara \\
9. & Nyoto Roso & Sumur Bandung \\
10. & Sederhana & Braja Sakti \\
11. & Tanpa nama & Braja Fajar \\
12. & Tanpa nama & Sri Rejosari \\
13. & Tanpa nama & Labuhan Ratu 2 \\
14. & Tanpa nama & Sumur Bandung \\
15. & Tanpa nama & Braja Sakti \\
16. & Tanpa nama & Braja Caka \\
17. & Tanpa nama & Braja Dewa \\
18. & Tanpa nama & Jepara \\
\hline
\end{tabular}




\section{KESIMPULAN}

Berdasarkan hasil penelitian dapat disimpulkan bahwa pengadaan bahan bahan baku dengan komponen enam tepat, yaitu waktu, tempat, harga, kuantitas, kualitas, dan jenis pada agroindustri aktif sudah tepat, karena sudah sesuai dengan harapan masing-masing agroindustri aktif. Tiga agroindustri keripik ubi kayu yang masih aktif memiliki nilai tambah positif $(\mathrm{NT}>0)$, dan dapat menyerap tenaga kerja, serta dapat meningkatkan perekonomian masyarakat di sekitar agroindustri. Faktor penyebab 18 agroindustri keripik ubi kayu di Kecamatan Way Jepara tidak lagi aktif berproduksi adalah cakupan pemasaran produk yang kurang luas, dan tingkat permintaan yang rendah terhadap produk keripik yang dihasilkan, belum adanya surat izin usaha, pengalaman berusaha yang kurang dimiliki, dan agroindustri keripik yang hanya berproduksi apabila ada pesanan saja.

\section{DAFTAR PUSTAKA}

Assauri S. 1999. Manajemen Produksi dan Operasi. Salemba Empat. Jakarta.

Ayu IF. 2012. Pengaruh Jumlah Mata Tunas Stek Terhadap Pertumbuhan dan Produksi Ubi Kayu (Manihot esculenta Crantz). Skripsi. Bogor. Fakultas Pertanian IPB.

Febriyanti, Affandi MI, dan Kalsum U. 2017. Analisis finansial dan nilai tambah agroindustri keripik pisang skala UMK di Metro. JIIA, 5(1): 48-56. http://jurnal.fp.unila.ac.id/index.php/JIA/arti cle/view/1674/1500. [27 Maret 2019].
Hayami. 1987. Agricultural Marketing And Processing In Upland Java. A Perspective From A Sunda Village. CGPRTC. Bogor.

Kartasapoetra AG. 1994. Teknologi Penanganan Pasca Panen. Rhineka Cipta. Jakarta.

Maharani CND, Lestari DAH., dan Kasymir E. 2013. Nilai tambah dan kelayakan usaha skala kecil dan skala menengah pengolahan limbah padat ubi kayu (onggok) di Kecamatan Pekalongan Kabupaten Lampung Timur. JIIA, 1(4): 298-303. http://jurnal.fp.unila.ac.id/index.php/JIA/arti cle/view/704. [27 Maret 2019].

Ntui, Uyoh EA, dan Affangideh U. 2006. Correlation and Genetic Variabillity in Cassava (Manihot esculenta Crantz). J. Of Food, Agric. \& Environ, 4(3/4): 147-150. https://www.researchgate.net/publication/26 6457807_Correlation_and_genetic_variabilit y_in_cassava_Manihot_esculenta_Crantz..[2 7 Maret 2019].

Sagala IC, Affandi MI., dan Ibnu M. 2013. Kinerja usaha agroindustri kelanting di Desa Karang Anyar Kecamatan Gedong Tataan Kabupaten Pesawaran. JIIA, 1(1): 60-65. http://jurnal.fp.unila.ac.id/index.php/JIA/arti cle/view/132. [27 Maret 2019].

Sari RY, Hasyim AI, dan Widjaya S. 2018. Rantai pasok dan nilai tambah keripik nangka pada agroindustri keripik panda alami di Kecamatan Gedong Tataan Kabupaten Pesawaran. JIIA, 6(3): 257-262. https://jurnal.fp.unila.ac.id/index.php/JIA/art icle/view/3022. [27 Maret 2019]. 